\title{
EVALUATION OF ETIOPATHOLOGY FOR HOARSENESS OF VOICE -A CLINICAL STUDY
}

\begin{abstract}
Authors: Ranveer Singh (1), Jaya Gupta*(2) Ausaf Ahmad (3) Devendra Kumar Mishra (4)
Authors Affiliations: (1) Professor, (2) Assistant Professor, (4) Audiologist, Department of E.N.T. (3) Statistician cum Assistant Professor, Department of Community Medicine, Integral Institute of Medical Sciences Dasauli Lucknow 226026
\end{abstract}

\begin{abstract}
Hoarseness of voice is one of the commonest symptoms found in ENT clinics. The present study is to assess etiopathology of hoarseness of voice at our center. The diagnostic potential of laryngeal endoscopy for different laryngeal lesions and its correlation with histopathology is also done. In this retrospective study 126 patients were included. The commonest etiology for hoarseness of voice was found to be chronic laryngitis (51.6\%) followed by malignancy (27.8\%) and vocal cord paralysis (15.1\%). Vocal abuse (33.3\%) and smoking (29.4\%) were found to be leading predisposing factors. Positive predictive value of laryngeal endoscopy for detecting malignant lesions was found to be $86.5 \%$. Fibreoptic laryngoscopy is a good tool for preliminary evaluation of hoarseness of voice. However, direct laryngoscopy should not be delayed if a diagnosis cannot be made by fibreoptic laryngoscopy
\end{abstract}

\section{KEYWORDS}

Hoarseness, Laryngeal endoscopy, Voice, Etiolopathology.

\section{INTRODUCTION}

DNA, fingerprints, retinal scan and voice can be used to identify a person. Voice is the primary mode of communication for human beings. "Although the voice is not visible to the eyes during speech production but its absence or malfunction is obvious". (Colton et al 1990)1. Alteration in the quality of voice significantly alters the quality of life. Additively its causes can vary from simple benign lesions to aggressively malignant causes. It could be faint hint of malignancy. Early suspicion and prompt evaluation is the center stone in its management. In the words of Chevalier Jackson- "Hoarseness is a symptom of utmost importance and calls for separate consideration as a distant signal of malignancy and other conditions" (Parikh 1991)2.

Our center is located in eastern Uttar Pradesh where consumption of tobacco and its related products (Banarasi Pan) is not just an addiction but very sadly a culture. This study aims for better understanding of hoarseness of voice- etiology, epidemiology, predisposing factors etc- in our region.

\section{AIMS AND OBJECTIVES}

1. Evaluate etiology of hoarseness

2. To estimate its incidence, predisposing factors, age and gender distribution.

3. To determine diagnostic potential of laryngeal endoscopy in different laryngeal lesions and its correlation with histopathology.

\section{MATERIAL AND METHODS}

The present study comprising of 126 cases of hoarseness of voice was carried out in the department of Otolaryngology in Integral Institute of Medical Science and Research, Lucknow from January 2019 to March 2020. All the cases presenting to ENT department with complaints of hoarseness of voice for more than 3 weeks duration were included in the study. Patients with congenital diseases, nasal or nasopharyngeal pathology, oral or oropharyngeal pathology and speech defects due to CNS lesions were excluded from the study. A proforma was designed on the basis of the objectives of the study. Detailed history, examination, both 
systemic and local ENT was done after taking informed consent from the patient. Larynx was also examined by 90* rigid laryngoscope followed by direct laryngoscopy with microlaryngoscopy (operating microscope using $400 \mathrm{~mm}$ lens) as and when required. Other investigations were performed as per the differential diagnosis of the patient.

\section{RESULTS}

A total of 21,267 patients attended the ENT OPD from January 2019 to March 2020. A total of 126 patients complained of hoarseness of voice. The incidence was noted to be $0.59 \%$ of all the cases. The age of the patients ranged from 9 years to 77 years. The overall mean age was 41.3 years. Hoarseness was most commonly found in the fourth decade $(43,34.1 \%)$ followed by the sixth decade $(25,19.8 \%)$ [Figure 1].

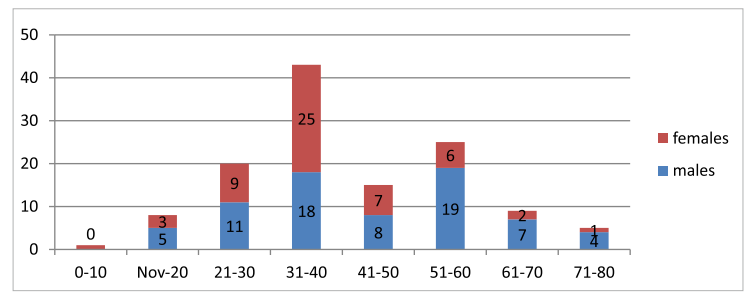

Figure : Age distribution.

Overall a male predominance was seen with male (72) to female (54) ratio of 1.3:1. Most of the patients presented within 3 months $(87,69.0 \%)$ of appearance of hoarseness. In our study, labourers/farmers $(36,28.6 \%)$ comprised majority of cases followed by homemakers (31, 24.6\%).

The most common predisposing factor was vocal abuse $(42,33.3 \%)$ followed by smoking (29, 23.0\%). In 51 (40.5\%) cases two predisposing factors were seen, most common combination being vocal abuse and smoking. Medical history was significant in 27 (21.4\%) patients with 10 (8.0\%) patients having more than one health problem. The most common illness was hypertension $(18,14.3 \%)$ followed by diabetes mellitus (15, 11.9\%) and tuberculosis (6, 4.76\%). Vocal fatigue (97, 77.0\%) followed by foreign body sensation throat/ frequent throat clearing (89,
71.6\%) were the most common complaints associated with hoarseness of voice.

After clinical evaluation and relevant investigations the most common aetiology of hoarseness was found to be chronic laryngitis $(65,51.8 \%)$ followed by the malignancy $(35$, 27.8\%). [Table 1]

\begin{tabular}{|c|c|c|}
\hline \multirow[t]{9}{*}{ Inflammatory } & & \\
\hline & Chronic laryngitis $(65,51.6 \%)$ & \\
\hline & Vocal nodule & $15.9 \%$ \\
\hline & LPRD & $15.1 \%$ \\
\hline & Vocal polyp & $11.1 \%$ \\
\hline & tubercular & $1.6 \%$ \\
\hline & leucoplakia & $4.8 \%$ \\
\hline & Reinke's odema & $1.6 \%$ \\
\hline & Sulcus vocal & $1.6 \%$ \\
\hline \multirow[t]{5}{*}{ Neoplastic } & & \\
\hline & Malignant $(35,27.8 \%)$ & \\
\hline & Hypopharyngeal & $17.5 \%$ \\
\hline & Laryngeal & $10.3 \%$ \\
\hline & $\begin{array}{c}\text { Benign (2 } 1.6 \%) \\
\text { Papilloma }\end{array}$ & $1.6 \%$ \\
\hline Neurological & Vocal cord palsy & $13.5 \%$ \\
\hline Functional & & $5.6 \%$ \\
\hline
\end{tabular}

Table 1: Etiological diagnosis

Laryngeal endoscopy was 100\% accurate in diagnosing functional and neurogenic disorders. It was also $100 \%$ accurate in diagnosing vocal nodule and reflux laryngitis. Two cases which clinically presented as laryngeal mass and suspected to be laryngeal papilloma on endoscopy were later on histologically diagnosed as laryngeal papilloma. On laryngeal endoscopy 37 patients were clinically diagnosed as having malignant lesion and 65 patients were diagnosed with benign lesion. In the 37 patients clinically diagnosed as having malignant lesion 5 
patients had a benign pathology. Out of 65 patients diagnosed with clinically benign lesion 3 were diagnosed with malignancy. Positive predictive value of laryngeal endoscopy for detecting malignant lesions was found to be $86.5 \%$. Accuracy of test for detecting malignancy was found to be $90.2 \%$.

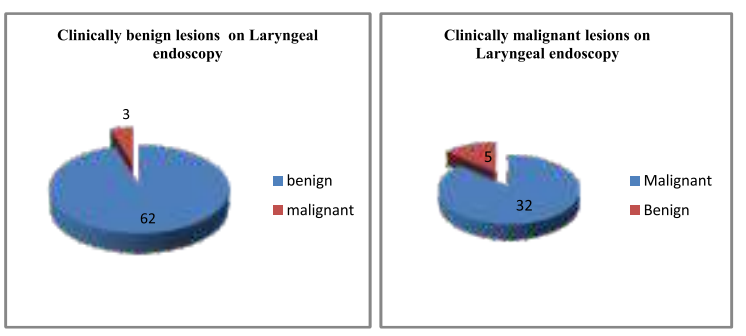

Figure: Results of clinically benign and malignant lesions on Histopathological examination respectively.

\section{DISCUSSION}

A variable incidence of hoarseness of voice has been recorded in various studies ranging from 0.21 (Vivek) 3 to $0.8 \%$ (Vengala) 4. The incidence $(0.59 \%)$ in our study was found to be within this range. Male to female ratio (1.3:1) was found to be closely related to that seen by Vengala4 (1.28:1), Rathi 5 (1.6:1). Majority of patients belonged to the fourth decade of life followed by the sixth decade. Male patients showed a higher percentage in the 6th decade and the females in the 4th decade. This observation was closely related to the findings by KS Pal6 which was a rural study as opposed to our study which caters to a mixed population. Vivek3 et al and Banjara8 et al also found maximum patients in the 4th decade followed by the 6 th decade.

Labourers and farmers (36, 28.6\%) constituted majority of cases followed by homemakers (31, $24.6 \%$ ); a similar observation was made by KS Pal6 and Baitha7.In our study, most of the patients $(69 \%)$ presented in the OPD within 3 months of appearance of symptoms. In studies by Banjara8 et al (61.35\%), S Vivek3 (47.1\%) and KS Pal6 et al (57.86\%) also most of the patients presented within 3 months duration. This again reinforces that patients with hoarseness of voice seek medical care much early.

Amongst the predisposing factors vocal abuse
(33.3\%) was found to be most common irrespective of the aetiology. As per Hirschberg9 et al a rapid change in the civilization, industrialization or professional requirements, more and more individuals are stressed to use their voice to a greater extent.

On the basis of vocal demands the patients were divided as per classification given by Koufman and Isaacson 10 (1991). Level 1 (elite vocal performers): included voice users like singers, actors, radio jockeys where even a slight vocal difficulty causes serious consequences to them and their careers. Level 2 (professional voice users): for whom moderate vocal difficulty would impede adequate job performance like clergymen, lecturers, teachers, politicians, public speakers etc. Level 3 (non vocal professionals): it includes teachers and lawyers. They can perform their jobs with slight or moderate voice problems; only severe dysphonia hampers adequate job performance. Level 4 (nonvocal /non professionals): which includes labourers homemakers and clerk. These are the persons whose work is not affected by dysphonia. Our findings were similar to the study by KS Pal6. [Table 2]

\begin{tabular}{|l|c|c|c|c|}
\hline & Batra11 & Banjara $^{8}$ & $\begin{array}{c}\mathrm{KSPal}^{6} \\
(2014)\end{array}$ & Present \\
study \\
\hline $\begin{array}{l}\text { Level 1 elite vocal } \\
\text { performers }\end{array}$ & $15.7 \%$ & $1.59 \%$ & $3 \%$ & $4 \%(5)$ \\
\hline $\begin{array}{l}\text { Level 2 professional } \\
\text { voice users }\end{array}$ & $15.7 \%$ & $3.59 \%$ & $15 \%$ & $13.5 \%(17)$ \\
\hline $\begin{array}{l}\text { Level 3 non vocal } \\
\text { professionals }\end{array}$ & $15.7 \%$ & $9.56 \%$ & $9 \%$ & $17.5 \%(22)$ \\
\hline $\begin{array}{l}\text { Level 4 non vocal non } \\
\text { professionals }\end{array}$ & $52.9 \%$ & $85.26 \%$ & $73 \%$ & $65 \%(82)$ \\
\hline
\end{tabular}

Table: $\mathbf{2}$ - Comparative analysis of vocal usage with related studies as per Koufman and Isaacson10 classification.

LPRD $(29,23.0 \%)$ was found to be the second most common predisposing factor followed by smoking (27, 21.5\%). Baitha S12 et al also found vocal abuse $(40.9 \%)$ to be the leading predisposing factor followed by smoking (25.45\%). In the study by Gosh SK13 vocal abuse was found in $72 \%$ cases. In another study 
smoking was found in $65 \%$ cases Rathi A5. The regional, occupational and habitual cultures define the predisposing factors in each of these studies.

The usage of tobacco and its preparation (smoking, tobacco chewing, and other forms of smokeless tobacco) was the second commonest predisposing factor if considered together. In the present study out of 35 patients who had malignancy of larynx and laryngopharynx 28 $(80 \%)$ patients had history of consuming tobacco- smoked or smokeless. This data roughly corresponds with that of Baitha S12 who found that $75 \%$ of cases of malignancy of laryngopharynx smoked tobacco. Smoking was the found to be highly significant factor for carcinoma of larynx and laryngopharynx. $(p<0.001)$

Present study included most of the patients with hoarseness along with vocal fatigue (77\%). Other associated symptoms were foreign body sensation throat (70.6\%), acid reflux/heart burn (70.6\%), pain in throat (55.5\%) and cough (51.6\%) in the descending order. No associated symptoms were present in 17 patients apart from hoarseness. From these 17 patients who had no other complaints other than hoarseness of voice, 7 patients were later proven to have malignancy. In our study the commonest aetiology was chronic laryngitis $(65,51.6 \%)$. The commonest etiology amongst females was chronic laryngitis (33 out of 54) and malignancy in males (29 out of 35). In studies by Parikh NP2 and Baitha S7 chronic laryngitis was the commonest aetiology comprising of $48 \%$ in each study, whereas in studies by Gosh SK13 and Batra K11 it was 6\% and $8 \%$ respectively.

Vocal nodule was the most common benign pathology seen in $15.9 \%$ cases. This category showed a reversal of male female ratio(1: 1.8) while in rest the male preponderance continued. All these patients had history of vocal abuse but only $10 \%$ of these smoked. Similar findings were observed by Banjara H8 et al wherein $11.95 \%$ cases of vocal nodules were seen with male to female ratio of $1: 1.7$. He also found that $90 \%$ of these patients had vocal abuse and $30 \%$ of these smoked. In studies by KS Pal6, Mehta AS14, Baitha S7, and Gosh SK13 vocal nodules were seen in $4 \%, 12.5 \%, 12.72 \%$ and $30 \%$ cases respectively.

Recent studies by S Vivek3 (2020, 1.4\%), Banjara H8 (2011, 0.8\%), Batra K11 (2004, 1\%) has shown that incidence of hoarseness of voice caused by tuberculosis has decreased over a period of time. Previous studies by Parikh NP2 (1991, 23\%) and Mehta AS14 (1985, 22.5\%) showed a relatively high number of cases with tuberculosis causing hoarseness of voice. The present study reaffirms the same fact with only $1.6 \%$ cases of tubercular laryngitis.

In the present study $15.1 \%$ of the patients were having hoarseness of voice due to reflux laryngitis, as compared to this Vengala RR4 found only $9.58 \%$ of the patients with reflux laryngitis. Smullen JL15 (1999) and Gregory ND16 (2012) have found an increasing incidence of hoarseness of voice due to reflux. This rising pattern can be attributed to the change in lifestyle of the population in general like change in food habits, increased stress at work. In contrast to these observations the percentage of cases found by Banjara H8 (2011) causing hoarseness of voice was negligible (0.8\%).

The second common aetiology after chronic laryngitis was malignancy $(35,27.8 \%)$. In studies by Amarnath SB 17, Batra K11, Parikh NP2 and Gosh SK13 the percentage of malignancy was $40 \%, 18 \%, 12 \%$ and $8 \%$ respectively. In the present study the commonest aetiology in male patients was malignancy. Amongst these 35 patients of malignancy 7 had no other complaint other than simple hoarseness of voice. It is this group of patient which needs utmost suspicion in early diagnosis.

As far as vocal cord palsy was concerned, we could not find any cause in 3 out of 17 patients. Two cases each were due to bronchogenic carcinoma, carcinoma oesophagus and post tubercular apical lung fibrosis. In five patients vocal cord palsy was iatrogenic and in 4 patients it was traumatic. In present study we found $5.6 \%$ 
cases of functional voice disorders with male to female ratio of 1:1.13.

\section{CONCLUSION}

Voice of person is a part of his being and is the main communication tool. Any change in voice alerts the patient and should alert the physician as well. The clinician should not hesitate to go for direct laryngoscopy if a diagnosis cannot be made by fibreoptic laryngoscopy without delay. As even slightest of delays can lead to the change in staging of the patients and indicate a more radical surgery. More so the epidemiological and etiological data varies vastly as in different studies and hence all patients should be thoroughly evaluated.

\section{REFERENCES}

1. Colton RH, Casper JK, Hirano M. (1990). In Understanding voice problem. Butter John P., editor. Baltimore: Williams and Wilkins; 1990. 1-9.

2. Parikh N.P. Aetiological study of 100 cases of hoarseness of voice. Indian J Otolaryngol. 1991; 4: 71-73.

3. S Vivek, G Shankar. Changing Trend in the Etiological Spectrum of Hoarseness of Voice in Rural India: A Prospective Hospital-Based Study. Ind J Otolaryngol Head \& Neck Surg. 2020;1-6.

4. Vengala RR, Kapilavaya N, Suraneni VR. Evaluation of Clinical Profile and Etiopathology for Hoarseness of Voice- $A$ study of 146 cases. Int J Med Res Rev. 2015; 3(2): 167-73.

5. Rathi A, Sharma S. Clinicopathological profile of hoarseness of voice. Int Jr Otorhinolaryngol Head Neck Surg. 2020; 6: 484.

6. Pal KS, Kaushal AK, Nagpure PS, Agarwal G. Etiopathological study of 100 patients of hoarseness of voice: in a rural based hospital. Ind J Otolaryngol Hea Nec Surg. 2014; 66(1): 40-5.

7. Baitha S, Raizada RM, Kennedy Singh AK, Puttewar MP, Chaturvedi VN. Clinical profile of hoarsens of voice. Ind J Otolaryngol Head Neck Surg. 2002; 54(1): 14-8.

8. Banjara H, Mungutwar V, Singh D, Gupta A.
Hoarseness of voice: a retrospective study of 251 Cases. Int J Phonosurg Laryngol. 2011; 1(1): 21-7.

9. Hirschberg J, Dejonckere PH, Hirano M et al (1995) Voice disorders in children. Int J Pediatric Otorhinolaryngol 32(suppl): S109-S125

10. Koufman JA, Isaacson G. The spectrum of vocal dysfunction. Otolaryngol Clin North Am. 1991; 24: 985-8.

11. Batra K, Motwani G, Sagar PC. Functional voice disorders and their occurrence in 100 patients of hoarseness as seen on fibreoptic laryngoscopy. Ind J Otolaryngol Head Neck Surg. 2004 Apr; 56(2): 91-5.

12. Baitha S, Raizada RM, Singh AK, Puttewar MP, Chaturvedi VN. Predisposing factors and aetiology of Hoarseness of voice. Indian $J$ Otolaryngol Head Neck Surg. 2004; 56(3): 186-190.

13. Gosh SK, Chattopadhyay S, Bora H, Mukherjee PB. Micro laryngoscopic study of 100 cases of hoarseness of voice. Ind J Otolaryngol Head Neck Surg. 2001; 53(4): 270-2.

14. Mehta AS. An etiological study of hoarseness of voice. A thesis submitted for master of surgery (Otorhinolaryngology), Gujarat University. 1985.

15. Smullen JL, Lejeune FE. Otolaryngologic manifestations of gastro esophageal reflux disease. J La State Med Soc. 1999; 151(3): 1159.

16. Gregory ND, Chandran S, Lurie D, Sataloff RT. Voice disorders in the elderly. J Voice. 2012; 26(2):254-8.

17. Amarnath S, Purushotham K. (2018). Aetiopathological study of hoarseness of voice: a clinical study. Int J Otorhinolaryngol Head Neck Surg. 2019 Jan; 5(1): 91-95.

\footnotetext{
${ }^{*}$ Corresponding author -

Dr Jaya Gupta, Assistant Professor

ENT department, Integral Institute of Medical Sciences Lucknow.226026. jayaguptaent@hotmail.com +919415979055
} 